\title{
OS ESPAÇOS DA AMBIGUIDADE: \\ OS PODERES LOCAIS E A JUSTIÇA \\ NA AMÉRICA ESPANHOLA \\ DO SÉCULO XVII
}

\begin{abstract}
Rafael Ruiz*
Doutor em História Social pela Faculdade de Filosofia, Letras e Ciências Humanas da

Universidade de São Paulo e professor adjunto de História da América na

Escola de Filosofia, Letras e Ciências Humanas da Universidade Federal de São Paulo
\end{abstract}

\section{Resumo}

Na América do século XVII, vigorou uma visão jurídica, conhecida como "probabilismo" que permitia aos poderes locais uma ampla margem de ambiguidade para negociar, adaptar, modificar ou rejeitar as leis reais, podendo ser considerados como agentes efetivos e eficazes na criação do direito na América.

\section{Pallavras-chave}

poderes locais na América • probabilismo • ambiguidade legal.

Correspondência

Escola de Filosofia, Letras e Ciências Humanas da Universidade Federal de São Paulo

Estrada do Caminho Velho, 333

07252-312 - Bairro dos Pimentas - Guarulhos - São Paulo

E-mail: rafael.ruiz@unifesp.br

* Agradeço à Fapesp pelo auxílio concedido para o desenvolvimento desta pesquisa. 


\title{
SPACES OF AMBIGUITY: LOCAL POWERS AND JUSTICE IN SPANISH AMERICA IN THE ITTH CENTURY
}

\begin{abstract}
Rafael Ruiz*
Doctor in Social History, Faculdade de Filosofia, Letras e Ciências Humanas of the

Universidade de São Paulo, and Professor of History of the Americas at Escola de Filosofia, Letras e Ciências Humanas of the Universidade Federal de São Paulo
\end{abstract}

\begin{abstract}
In the Americas in the 17th century, there was a predominant legal view called "probabilism", which gave the local powers enough ambiguity to negotiate, adapt or reject royal laws. These local powers can therefore be considered true, efficient agents in the creation of Latin American law.
\end{abstract}

\section{Keywords}

local powers in the Americas • probabilism • legal ambiguity.

\section{Contact}

Escola de Filosofia, Letras e Ciências Humanas da Universidade Federal de São Paulo

Estrada do Caminho Velho, 333

07252-312 - Bairro dos Pimentas - Guarulhos - São Paulo

E-mail: rafael.ruiz@unifesp.br

* I would like to thank Fapesp for their support 


\section{Introdução}

O objetivo deste artigo é mostrar que, na América do século XVII, principalmente na América espanhola, os poderes locais dos vice-reinados tinham uma ampla margem de negociação para adaptar, modificar ou rejeitar as leis reais, de maneira que poderiam ser considerados como agentes efetivos e eficazes na criação do direito na América.

Há duas premissas que fundamentam este trabalho e ambas podem ser encontradas na obra de Richard Morse. A primeira, quando Morse caracteriza a Modernidade ibérica como uma época marcada pela visão "probabilística", em que "a estratégia probabilista proibia afirmar uma certeza maior que a permitida pelo tema, mas, ao fazê-lo, autorizava opiniões prováveis quando a certeza era impossível". ${ }^{1}$ Será dentro dessas opiniões prováveis dos diferentes teólogos, moralistas e juristas do século XVII que este artigo procurará encontrar os espaços de ambiguidade dos poderes locais na América.

A segunda, quando escreve sobre os diferentes momentos da Modernidade no mundo ibérico e no anglo-saxônico, ${ }^{2}$ a partir do qual se pode constatar a existência de dois tempos ou momentos no longo período colonial. O primeiro momento - que é o objeto específico desta pesquisa - decorre entre os séculos XVI e XVII, chegando ainda à metade do XVIII, e se caracteriza por ser um período em que os juízes e, de maneira geral, aqueles que detinham o poder de tomar decisões a partir das leis, realizavam o seu ofício caso a caso, de maneira circunstanciada e atendendo principalmente aos costumes locais e às diferentes opiniões dos juristas. O segundo momento começaria a partir da segunda metade do XVIII até o final do período colonial e estaria caracterizado pela prevalência da lei sobre os costumes e sobre as diferentes opiniões dos juristas, de maneira que, em lugar de diferentes costumes ou leis para diferentes casos ou cidades, haveria uma única lei que seria aplicada de forma homogênea para todos.

Depois de uma pesquisa de dois anos, pude analisar os textos de oito juristas, moralistas e teólogos, seis da primeira metade do século XVII e dois da segunda metade, e ainda a obra do teólogo e moralista dominicano italiano Daniel Concina, publicada em 1773, que dialoga e contesta as doutrinas e teorias desses juristas, alguns deles citados explicitamente. As obras e os seus autores são os seguintes: Tratado que contiene tres pareceres graves en derecho de fray Miguel Agia,

1 MORSE, Richard. O espelho de Próspero. Cultura e ideias nas Américas. São Paulo: Companhia das Letras, 1998, p. 35.

2 Idem, p. 60. 
publicado em Lima, em 1604: ${ }^{3}$ Veriloquium en reglas de Estado, segun derecho diuino, natural, canonico y ciuil y leyes de Castilla, enderezado a la conseruacion de la auctoridad del catholico don Phelipe Tercero do jurista espanhol Thomás Cerdán de Tallada, publicado em Valencia, em 1604; ${ }^{4}$ Política para corregidores y señores de vasallos en tiempos de paz y de guerra y para jueces eclesiásticos y seglares do jurista espanhol Jerónimo Castillo de Bobadilla, publicado em Medina del Campo, em 1608, ${ }^{5}$ Arte legal para el estudio de la jurisprudencia escrita pelo espanhol Francisco Bermúdez de Pedraza e publicada em Salamanca em 1612; ${ }^{6}$ Tractatus de legibus ac Deo Legislatore do jesuíta espanhol Francisco Suárez e publicado em primeira edição em Coimbra, em 1612; Practicarum observationum sive decisionum supremi senatu Regni Lusitaniae do jurista português Jorge de Cabedo, publicado em Antuérpia, em $1620{ }^{8}$ Theologia moralis in quinque libros partita, Bambergae: Editio Sexta, Joan Martius Schonwetteri, escrita pelo jesuíta austríaco Paulo Laymann, publicada em 1677, ${ }^{9}$ Tractatus de Donationibus iurium et bonorum regiae Coronae escrita pelo jurista português Domingos Antunes Portugal, publicada em 1699; ${ }^{10}$ e Theologia christiana dogmático-moral, compendiada en dos tomos do dominicano italiano Daniel Concina, publicada, na sua versão castelhana, em terceira edição em $1773 .{ }^{11}$ Além desses autores,

3 A obra consultada em concreto é a edição publicada por AYALA, Francisco Javier. Servidumbres personales de índios. Sevilla: Publicaciones de la Escuela de Estudios Hispano-americanos, 1946, que contém, além de um estudo preliminar, o texto dos três pareceres e o texto da Real Cédula de 24 de novembro de 1601, que é a lei interpretada, nos pareceres, por fray Miguel Agia.

4 CERDÁN DE TALLADA, Thomás. Veriloquium en reglas de Estado, segun derecho diuino, natural, canonico y ciuil y leyes de castilla, enderezado a la conseruacion de la auctoridad del catholico don Phelipe Tercero. Valencia: en casa de Iuan Chrysostomo Garriz, 1604.

5 CASTILLO DE BOBADILLA, Jerônimo. Politica para corregidores y señores de vasallos en tiempos de paz y de guerra. Medina del Campo: por Christoval Lasso e Francisco Garcia, 1608.

6 BERMÚDEZ DE PEDRAZA, Francisco. Arte legal para el estudio de la jurisprudência. Salamanca: Imprenta de Antonia Ramírez, Viúda, 1612 e Arte legal para estudiar la jurisprudencia nuevamente corregido y añadido en esta segunda edición. Madrid: por Francisco Martínez, a costa de Domingo Gonçalez, 1633.

7 SUÁREZ. Francisco. De Legibus III. Madrid: Corpus Hispanorum de Pace, 1974.

8 CABEDO, Jorge de. Practicarum observationum sive decisionum supremi senatu Regni Lusitaniae. Antuerpiae: Ioannem Keerbergium, 1620.

9 LAYMANN, P. Theologia moralis in quinque libros partita. Bambergae: Editio Sexta, Joan Martius Schonwetteri, 1677.

${ }^{10}$ PORTUGAL, Domingos Antunes. Tractatus de donationibus iurium et bonorum regiae Coronae. Lugduni: Editio secunda Lugdinensis, Adisson, 1699.

${ }^{11}$ CONCINA, Daniel. Theologia christiana dogmático-moral, compendiada en dos tomos. Traducida al idioma castellano y añadida en muchas partes de las obras del mismo autor por el p. d. Joseph Sánchez de la Parra. Madrid: Tercera Impresión, en la oficina de la viúda de Manuel Fernández, 1773. 
analisei também o documento conhecido como Apologia pro paulistis, de 1684, atribuído ao jesuíta Jacob Rolland. ${ }^{12}$

Diante das pesquisas realizadas, parece-me que se pode afirmar que a legislação metropolitana na América, principalmente na América espanhola do século XVII, respondia a uma forma de ver o mundo jurídico onde os vice-reis, as audiências, os "cabildos", as câmaras e todos aqueles que, de alguma maneira, detinham poderes judiciais, podiam reformular ou rejeitar as leis reais, precisamente pelo fato de que, de acordo com a visão jurídica própria desse primeiro momento, os agentes mais qualificados para realizar a justiça seriam aqueles que estavam mais próximos dos locais para onde eram enviadas essas mesmas leis. Isto conferia um amplo espaço de ambiguidade e de manobra aos agentes locais do poder para agir de acordo com os seus próprios interesses e os das diferentes redes locais estabelecidas na construção das bases políticas, econômicas, jurídicas, administrativas e sociais na América. ${ }^{13}$

A finalidade deste artigo é a de mostrar como os espaços de ambiguidade que os poderes locais da América espanhola detinham no século XVII foram facilitados pela corrente probabilística, dominante no campo da teologia moral católica da época, pelo papel atribuído à consciência dos agentes judiciários locais, e pela força vinculante dos costumes que, com muita frequência, prevaleciam sobre as leis reais.

\section{0 probabilismo como corrente de pensamento}

O probabilismo era uma das várias escolas em que a teologia moral católica se dividiu ao longo do século XVII. Diante de uma dúvida concreta à hora de praticar um ato (por exemplo, à hora de dar uma sentença), a doutrina dividia-se, defendendo ou bem a hipótese de agir da forma mais segura (era conhecida como "tuciorismo"), ou bem a hipótese de seguir a opinião mais certa ou mais prová-

${ }^{12}$ ZERON, Carlos Alberto de M. R. e RUIZ, Rafael. A força do costume, de acordo com a Apologia pro paulistis (1684). ALMEIDA, Marta de e VERGARA, Moema de Rezende (org.). Ciência, história e historiografia. São Paulo/Rio de Janeiro: Via Lettera/Mast, 2008, p. 359-376.

${ }^{13}$ Sobre a questão da "ambiguidade" como uma forma ou estilo da praxe política, administrativa e legislativa da Coroa, pode-se consultar ZERON, Carlos Alberto de Moura Ribeiro. Ligne de foi: La Compagnie de Jésus et l'esclavage dans le processus de formation de la société coloniale en Amérique portugaise (XVIe.-XVIIe. siécles). Paris: Honoré Champion Éditeur, 2009, principalmente as páginas 357-380, em que o autor defende a ideia de que essa ambiguidade responderia a uma posição da Monarquia para ajustar politicamente os diferentes grupos de interesses no nível local. 
vel (conhecida como "probabiliorismo") ou bem a hipótese de seguir a opinião simplesmente provável, que é a que estamos discutindo neste artigo. ${ }^{14}$

O problema da corrente probabilística, como assinala Paolo Prodi, era que a discussão sobre a decisão mais ou menos provável não era um debate restrito apenas ao campo da moral, mas tinha também uma eficácia concreta na esfera jurídica. ${ }^{15}$ Uma sentença judicial não tinha apenas um significado moral, mas tinha principalmente uma transcendência jurídica, da qual resultava uma decisão que criava laços jurídicos determinados. Embora muitos juristas estivessem empenhados no esforço de separar as esferas do moral-eclesiástico e do civiljurídico, na pretensão de consolidar um Estado forte e autônomo com relação à Igreja, ${ }^{16}$ esse esforço não prevaleceu até bem entrado o século XVIII porque, como afirma Paolo Prodi, "a hegemonia da norma positiva escrita, que se afirma durante a Idade Moderna, deriva não apenas de um processo de racionalização e secularização, que se formou com o iluminismo como reação e oposição ao Antigo Regime, mas tem a sua própria gênese dentro do Antigo Regime". ${ }^{17} \mathrm{De}$ fato, ao longo de todo o século XVII, pode-se acompanhar o desenvolvimento e a evolução de duas tendências: a primeira, herdeira da tradição do direito romanocanónico da Idade Média, que estruturou e fundamentou as leis civis reais $;{ }^{18}$ a segunda, secundando as pretensões de autonomia e soberania dos novos Estados modernos, e que pretendia a "redução dos privilégios jurisdicionais da Igreja e a sua colocação ao serviço do príncipe". ${ }^{19}$

Contudo, o debate entre canonistas e civilistas não se deu apenas para fortalecer a Igreja ou o Estado, mas também consistiu numa "contenda pelo poder sobre as consciências, no momento em que as leis positivas ainda se encontram frágeis e em formação, fragmentadas, contraditórias, ansiosas por construir a plataforma dos novos Estados territoriais e submetidas a críticas ferozes; tal contenda se dá também no momento em que os juízes ainda não renunciaram ao poder tradicional de criar o direito, e não apenas de aplicá-lo, em que as Igrejas renunciaram a grande parte da sua jurisdição canônica tradicional e buscam

\footnotetext{
${ }^{14}$ Sobre as diferentes escolas moralistas do século XVII, veja-se PINCKAERS, Servais Th. Las fuentes de la moral cristiana. Trad. de Juan José Garcia Norro. Pamplona: EUNSA, 2000.

${ }_{15}$ PRODI, Paolo. Uma história da justiça. São Paulo: Martins Fontes, 2005, p. 167.

${ }^{16}$ Sobre esse tema, veja-se HOMEM, António Pedro Barbas. Iudex perfectus. Função jurisdicional e estatuto judicial em Portugal, 1640-1820. Coimbra: Almedina, 2003.

${ }^{7}$ PRODI, Paolo, op.cit., p. 431.

${ }^{18}$ Cf. HOMEM, António Pedro Barbas, op.cit., p. 118.

${ }^{19}$ Idem, p. 86.
} 
recuperá-la no plano do direito das consciências". ${ }^{20}$ Trata-se, portanto, de um momento em que essas duas correntes ainda não se encontravam nem plenamente superadas nem plenamente firmadas e em que diversos autores defendiam uma ou outra posição.

Parece que, do ponto de vista da moral, o primeiro que começou a elaborar a doutrina probabilística foi Bartolomé de Medina quem, comentando uma afirmação de são Tomás de Aquino, na Summa theologiae, escrevera que lhe parecia que se poderia seguir uma opinião provável, mesmo que a opinião oposta fosse mais provável. ${ }^{21}$ Por outro lado, segundo Prodi, do ponto de vista jurídico, o primeiro expoente dessa doutrina foi o chanceler da Universidade de Paris, Jean Gerson (1363-1429), cuja doutrina será “o divisor de águas nos séculos posteriores, até o século XVIII". ${ }^{22}$ Para Gerson, a questão central estava colocada no foro em que o homem devia responder pelo seu pecado, que poderia torná-lo réu de morte eterna e, a partir daí, explica Prodi, "a distinção entre as leis só podia ser entre aquelas destinadas à vida civil e política e aquelas destinadas à vida espiritual". ${ }^{23}$ A conclusão de todo esse elaborado raciocínio de distinções legislativas era que nenhum legislador poderia punir nenhum homem no foro interno da consciência. ${ }^{24}$

O probabilismo desenvolveu-se no mundo ibérico como uma corrente de pensamento que estava vincada pela ideia de que as decisões e sentenças dos juízes poderiam seguir a opinião provável e não necessariamente a opinião certa. Esta opinião normalmente apoiava-se ou bem nas doutrinas e opiniões dos juristas de renome, ${ }^{25}$ ou bem nos diferentes costumes locais e, muitas vezes, poderia ser inclusive contrária às leis metropolitanas. Por outro lado, essa mesma doutrina defendia que os juízes deveriam seguir não propriamente a lei, mas principalmente a sua própria consciência e, nesse sentido, tornava-se necessário que os juízes levassem em conta as circunstâncias e as peculiaridades locais dos casos concretos.

Essa corrente doutrinária teve uma influência e uma força efetivas não apenas na Espanha, mas também na América, provocando intensos debates, de tal

${ }^{20}$ PRODI, Paolo, op. cit., p. 398.

${ }^{21}$ MARTEL PAREDES, Víctor Hugo. El lugar del probabilismo en las ideas políticas del Perú. Solar. Lima, no 3, año 3, 2007, p. 14.

${ }^{22}$ PRODI, P., op. cit., p. 196.

${ }^{23}$ Ibidem.

${ }^{24}$ Idem, p. 197.

${ }^{25}$ Barbas Homem afirma que a aplicação da opinião dos doutores ou a vinculação aos precedentes decididos traduz, em Portugal, uma preferência geral pelo "direito prudencial". Cf. op. cit., p. 67. 
forma que "não é possível entender todo o século XVII e mesmo até toda a época colonial, se não se tiverem em conta essas discussões". ${ }^{26}$ Os agentes do poder local e as autoridades judiciais coloniais, principalmente os vice-reis, podiam não apenas executar ou adaptar as leis metropolitanas, mas também modificálas, ignorá-las ou mesmo desobedecê-las sem, por isso, se constituírem num núcleo de oposição ou desobediência à Monarquia, visto que a própria Coroa compartilhava dessa mesma visão jurídica ${ }^{27} \mathrm{~A}$ consciência do vice-rei, apoiada ou bem nas opiniões emitidas pelos diferentes doutores, juristas e moralistas, ou bem nas especificidades dos costumes locais, era um dos vários critérios que permitiam criar esferas de negociação entre o poder real, o poder local e as elites locais, para resolver os conflitos de acordo com os seus próprios interesses. Dessa forma, a consciência dos juízes passou a adquirir um grau de autonomia extremamente amplo no mundo civil e político, a tal ponto que, em 1769, o rei Carlos III convocou diferentes concílios eclesiásticos em todos os reinos das Índias, ${ }^{28}$ para que se tratasse especificamente desse assunto, porque, conforme o seu parecer, a contínua aplicação dos princípios da doutrina probabilística estava esgarçando as relações e os vínculos de fidelidade e de obediência de todos os súditos. Tratava-se, portanto, de um problema que não era apenas moral, mas principalmente civil e político. ${ }^{29}$

Em 1773, no mesmo ano em que, por meio da bula Dominus ac Redemptor, o papa Clemente XIV suprimira a Companhia de Jesus, publicou-se, em Madri, a obra do italiano Daniel Concina, traduzida para o castelhano e contando com o apoio do papa Benedicto XIV, Theologia christiana dogmático-moral, compendiada en dos tomos. O tradutor da obra, o padre de la Parra, ao explicar a importância da mesma, queixava-se de que, nos reinos da Espanha, a maior parte dos juristas e teólogos eram partidários da interpretação probabilística da lei que, na sua opinião, era a responsável pelo estado de corrupção e de decadência em que se encontravam não apenas os indivíduos, mas também os Estados, de tal

${ }^{26}$ MUÑOZ GARCÍA, Ángel. Diego de Avendaño, 1594-1698: filosofía, moralidad, derecho y política en el Perú colonial. Lima: UNMSM, Fondo Editorial, 2003, p. 66.

${ }^{27}$ ZERON, Carlos Alberto de Moura Ribeiro. Ligne de foi: La Compagnie de Jésus et l'esclavage dans le processus de formation de la société coloniale en Amérique portugaise (XVIe.-XVIIe. siécles). Paris: Honoré Champion Éditeur, 2009.

${ }^{28}$ MARTEL PAREDES, Víctor Hugo El lugar del probabilismo en las ideas políticas del Perú. Solar. Lima, nº 3, año 3, 2007, p. 11-22.

${ }^{29}$ Idem, p. 12. 
forma que se podia afirmar que "pasaron los siglos de oro, y les han sucedido los de barro y corrupción". ${ }^{30}$

Embora a obra de Concina fosse um tratado de teologia dogmática e tivesse sido publicada em 1773, dava conta de uma corrente de pensamento jurídico que não apenas a Igreja, mas também o Estado, consideravam perniciosa e perigosa para o equilíbrio social, o qual parece ser suficiente para deduzir a penetração e a influência dessa corrente durante os séculos XVII e XVIII. De fato, se os máximos poderes religiosos e políticos da época estavam preocupados com as dimensões políticas, sociais e morais que essas doutrinas estavam provocando na sociedade, essas questões não poderiam ser apenas discussões filosóficas e teológicas, mais ou menos vagas e imprecisas, de interesse restrito para teólogos e religiosos. Pelo contrário, seriam sim questões que marcaram toda a vida da sociedade do mundo ibérico durante o século XVII.

A questão, para a América espanhola, colocava-se de forma ainda mais acentuada do que na Espanha, porque a quantidade de casos particulares novos que surgiam continuamente no território americano tornava quase impossível aplicar exatamente as leis gerais aos casos concretos. ${ }^{31}$ Dessa maneira, as circunstâncias locais configuravam-se, efetivamente, como elementos que permitiam aos magistrados locais determinar de forma concreta o que viesse determinado de maneira geral nas Cédulas Reais, de maneira que as situações concretas que se apresentavam serviam como circunstâncias, a partir das quais a lei era entendida, interpretada e colocada em prática ou, em muitas outras ocasiões, ignorada. ${ }^{32}$

Esse era o teor, por exemplo, do parecer de fray Miguel Agia, secretário do Comissário Geral da Ordem de São Francisco, em Lima, para dom Luis de Velasco, vice-rei, governador e capitão geral do Vice-Reinado do Peru. O texto do parecer é o "Tratado que contiene tres pareceres graves en Derecho", publicado em Lima, em $1604 .{ }^{33}$ Agia elaborou três pareceres, analisando um por um os artigos da Real Cédula de 24 de novembro de 1601, que proibia os trabalhos indígenas realizados em benefício particular dos "encomenderos", conhecidos como "servidumbres personales", e concluía que a Cédula Real não precisava

${ }^{30}$ CONCINA, Daniel, op. cit., p. I, n. 1.

${ }^{31}$ MARTEL PAREDES, Víctor Hugo. El lugar del probabilismo en las ideas políticas del Perú. Solar. Lima, no 3, año 3, 2007, p. 14.

${ }^{32}$ MUÑOZ GARCÍA, Ángel, op. cit., p. 70-71.

33 A obra consultada em concreto é a edição publicada por AYALA, Francisco Javier. Servidumbres personales de índios. Sevilla: Publicaciones de la Escuela de Estudios Hispano-americanos, 1946, que contém, além de um estudo preliminar, o texto dos três pareceres e o texto da Real Cédula de 24 de novembro de 1601, que é a lei interpretada, nos pareceres, por fray Miguel Agia. 
ser aplicada e que podia ser modificada pelo vice-rei, porque não era um "mero executor sin conoscimiento como suelen ser los meros tales executores" ${ }^{34}$ Ele era, na verdade, um "juez arbitro (si licitamente puede llamarse por este nombre) pues tiene autoridad su Señoria de añadir, y quitar, alterar, mudar, remouer, executar, y dexar de executar lo que viere que conuiene al bien comun de la Republica". ${ }^{35}$

\section{Os princípios do probabilismo}

O princípio mais geral das doutrinas probabilísticas era o seguinte: "el que obra con probabilidad, obra prudentemente". ${ }^{36}$ Estabelecia-se, portanto, uma relação intrínseca entre "prudência" e "opinião provável". Agir com prudência, à hora de elaborar uma sentença, era uma das funções mais importantes dos magistrados judiciais. Tratava-se de uma visão aristotélica sobre a justiça e o "justo meio": ${ }^{37}$ a sentença justa, com frequência, era aquela que decorria da consideração das circunstâncias dos fatos e dos diferentes costumes locais ${ }^{38}$ e, portanto, se um vice-rei seguisse prudentemente uma opinião provável, para o bem da República e o estabelecimento do bom governo, mesmo que esta decisão implicasse uma alteração ou adaptação das leis reais, estaria decidindo conforme a justiça. Nesse sentido, por exemplo, é recorrente encontrar, nos pareceres do Conselho de Índias, decisões que remetiam ao que "melhor parecer ao vice-rei do Peru" ou a permissão para decidir "conforme a disposição das coisas", confirmando a importância que se dava à consciência do vice-rei ou às próprias circunstâncias locais. ${ }^{39}$

Um segundo princípio era aquele que defendia que a"lex dubia non est lex. La Ley que está en duda no es Ley". ${ }^{40}$ A transformação de um lei "clara" em "duvidosa", ao longo do século XVII, aconteceu, segundo a obra do p. Concina, pelo elevado número de opiniões diferentes, divergentes ou mesmo contrárias, que os teólogos e juristas foram realizando por meio de glosas ou comentários às leis reais. Dessa maneira, como afirmava o tradutor do p. Concina, era comum

\footnotetext{
${ }^{34}$ AGIA, op. cit., p. 115.

${ }^{35}$ Ibidem.

${ }^{36}$ CONCINA, D., op. cit., Prólogo, V, n. XV.

${ }^{37}$ Sobre a influência do aristotelismo e as suas vertentes hispânicas no tuciorismo e neoestoicismo, pode-se consultar PÉREZ, Aranda, RODRIGUES, Francisco José e DAMIÃO, José (eds.). De re publica Hispaniae. Una vindicación de la cultura política en los reinos ibéricos de la primera Modernidad. Madrid: Sílex, 2008, p. 34.

${ }^{38}$ RUIZ, Rafael. Duas percepções da justiça nas Américas: Prudencialismo e legalismo. Anais eletrônicos do VIII Encontro Internacional da ANPHLAC. Vitória, 2008.

${ }^{39}$ A.G.I. Indiferente, 742, n. 114.

${ }^{40}$ CONCINA, D., op. cit., Prólogo, VI, n. XVII.
} 
encontrar, para cada lei, um enorme número de comentadores que emitiam uma opinião ou a sua contrária. ${ }^{41}$ Esse modo de proceder era uma forma de relativizar a lei, porque se entendia que, se sobre uma lei concreta existiam várias opiniões divergentes, então essa lei era considerada duvidosa e, sendo assim, já não podia ser entendida como lei, nem tinha força coativa. ${ }^{42}$

O terceiro princípio da doutrina probabilística era assim formulado: "En Dios se dan dos leyes eternas per se $y$ per accidens, o directa y reflexa, o antecedente $y$ consiguiente". ${ }^{43} \mathrm{O}$ princípio tal como está formulado tinha muitas conotações teológicas e morais, que estão além do campo de análise deste artigo. Contudo, interessa destacar uma consequência concreta na vida civil e política da sociedade: mesmo que o magistrado errasse ao decidir uma sentença concreta, deveria seguir o que determinava a sua consciência, porque "el dictamen de nuestra conciencia es verdadero, aun quando el hombre erra con error vencible". ${ }^{44}$ A consciência de quem devia julgar passava, dessa forma, a ser um dos critérios mais importantes para fundamentar a decisão, como indica Paolo Prodi, quando percebe que, nesse momento, está se formando "o esboço de uma divisão já completa entre o foro da lei e o foro da justiça divina: a única ligação está na consciência do juiz" ${ }^{45}$ Nesse sentido, também para citar apenas um exemplo, é interessante verificar como a Real Audiência de La Plata informava ao Conselho de Índias que, de fato, juntamente com o vice-rei Velasco tinham decidido "suspender a publicação e execução" ${ }^{46}$ da Real Cédula sobre o trabalho dos índios, que tinha sido objeto dos pareceres do fray Miguel Agia.

Como já salientaram muitos historiadores, ${ }^{47}$ os séculos XVI e XVII foram um palco onde se debateu a institucionalização de um Estado forte frente às correntes de pensamento que, como a probabilística, relativizavam de uma ou outra forma a força desse poder. Para Prodi, não foi por acaso que o principal palco desse debate acontecesse na Espanha, "onde se põe em prática o maior laboratório político europeu para a construção do Estado, e que essa construção atravessa estágios históricos muito diferentes desde o início até o final do

\footnotetext{
41 Idem.

${ }^{42}$ Ibidem.

${ }^{43}$ CONCINA, D., op. cit., p. 144, n. 1.

${ }^{44}$ Idem, p. 145, n. 2.

${ }^{45}$ PRODI, Paolo, op.cit., p. 211.

${ }^{46}$ A.G.I. Charcas, 31.

${ }^{47}$ Para uma historiografia atualizada de autores portugueses e espanhóis, veja-se o recente trabalho de PÉREZ, Aranda, RODRIGUES, Francisco José e DAMIÃO, José (eds.). De re publica Hispaniae. Una vindicación de la cultura política en los reinos ibéricos de la primera Modernidad. Madrid: Sílex, 2008.
} 
século". ${ }^{48}$ Também não foi por acaso que a obra do italiano Daniel Concina fosse traduzida para o castelhano, visto a existência de um grande número de autores que defendiam a possibilidade de se seguir a opinião que, em consciência, o juiz visse como simplesmente provável.

Em resumo, a doutrina probabilística atribuía à consciência dos magistrados locais o poder de decidirem prudentemente sobre as formas de aplicação ou não aplicação das leis metropolitanas. A interpretação de uma lei régia de acordo com a convicção em consciência do juiz tornava-se um instrumento legal, que colocava nas mãos das autoridades locais o poder não apenas de executar e adaptar as leis, mas principalmente o poder de ignorá-las e, inclusive, de não obedecê-las.

Agir de acordo com a opinião provável era agir prudentemente e, nesse sentido, a prudência, aliada à consciência individual, convertia-se no critério que determinava a proporcionalidade com que cada lei régia deveria ser aplicada em cada território. Era, na verdade, o princípio regulador das diferentes medidas que uma mesma lei da Coroa podia ter na América e foi na América, como lembra Martel de Paredes, que a doutrina probabilística permitiu "a ascensão da Modernidade" na vida colonial peruana. ${ }^{49}$

\section{$\mathbf{O}$ papel da consciência das autoridades locais}

O que estava em discussão, no século XVII e no mundo ibérico, era um debate entre o poder totalizante ou universalizante da lei em confronto com as circunstâncias particulares e concretas dos fatos e dos casos. A maioria dos autores probabilistas defendia a ideia de que, sendo a lei, inclusive a lei de Deus, necessariamente geral e universal, era sempre necessário realizar uma tarefa de interpretação e, para tanto, o intérprete (normalmente, o juiz, o governador ou o vice-rei) tinha de seguir a sua própria consciência que, diante de situações novas ou desconhecidas, muitas vezes ficava em dúvida perante diferentes possibilidades de ação. Nesses casos, como já disse, a doutrina probabilística defendia que, para agir de forma correta e justa, era suficiente seguir a opinião simplesmente provável.

Na opinião de Prodi, isso significava que "a epiqueia, como poder interpretativo da lei por parte do juiz, é (...) cada vez mais uma interpretatio legis, referência a uma moderação na interpretação da lei, a uma mitigação do texto

\footnotetext{
${ }^{48}$ Idem, p. 227.

${ }^{49}$ MARTEL PAREDES, Víctor Hugo. El lugar del probabilismo en las ideas políticas del Perú. Solar. Lima, no 3, año 3, 2007, p. 12.
} 
escrito da lei" ${ }^{50}$ Por um lado, suavizava-se o rigor da lei e, por outro, adquiria-se uma ampla margem de negociação à hora de dar a sentença, levando em conta não apenas as circunstâncias do fato, mas também os diferentes interesses que se achassem envolvidos, já que sempre seria possível, como Concina lamentava no seu Tratado, encontrar autores e doutores em direito que teriam opiniões desencontradas, de maneira que o governador, ou o presidente da Audiência ou o vice-rei poderiam seguir aquela opinião que considerassem provável. ${ }^{51}$ É interessante, nesse sentido, a solução encontrada pelo Conselho de Índias para um caso em que não se sabia, à distância, como agir mais prudentemente: tratava-se de decidir sobre a nomeação dos governadores de Tucumán e Rio de la Plata, por volta de 1593, e o Conselho estava preocupado "por lo mucho que conviene que se acierte en esto". ${ }^{52}$ A solução foi redigir duas cartas para o vice-rei do Peru, nomeando don Pedro Mercado e don Fernando de Zárate, porém "no van firmadas" para que o vice-rei visse e decidisse como "más le pareciere a mi servicio $y$ bien de aquellas provincias". ${ }^{53}$

Parece-me que o espaço de ambiguidade que se abriria com essa decisão era o suficientemente amplo para que o vice-rei pudesse agir conforme o seu próprio arbítrio. E parece-me que seria dentro desta praxe judiciária que deveria ser entendido o célebre aforismo de "obedece-se, mas não se cumpre", aplicado à legislação metropolitana. Em minha opinião, o não cumprimento da lei expresso no aforismo não significaria que a legislação fosse oscilante ou confusa, mas, pelo contrário, queria significar que se tratava de uma legislação que era aplicada de forma circunstanciada e atendendo aos casos concretos e locais específicos. Aceitava-se, na América, o princípio legal, reconhecia-se a autoridade régia para editar leis, mas a sua aplicação e obrigatoriedade passavam a depender das circunstâncias locais.

Seguir a própria consciência era, para os juristas, elaborar um juízo (nas palavras de Concina, "dar um dictame") sobre um caso concreto, a partir do seu entendimento, tendo em conta não apenas a lei, mas principalmente as circunstâncias concretas que especificavam o caso e que eram estudadas nos tratados de teologia moral, uma disciplina que tinha começado a diferenciar-se do direito canônico, transformando-se em ciência autônoma e que se encontrava entrelaçada e em constante diálogo com o direito positivo. ${ }^{54}$

\footnotetext{
${ }^{50}$ PRODI, P., op. cit., p. 171.

${ }^{51}$ Cf. CONCINA, D., op. cit., p. 109, n. 13.

${ }^{52}$ A.G.I., Indiferente, 742, n. 114.

${ }^{53}$ Ibidem.

${ }^{54}$ Cf. PRODI, P., op. cit., p. 205. Para todo esse processo de separação e autonomia do direito civil com relação ao canônico, em Portugal, veja-se a obra já citada de Barbas Homem.
} 
Para entender melhor esta questão, que me parece decisiva, gostaria de explicar um aspecto da obra do jurista espanhol Francisco Bermúdez de Pedraza, ${ }^{55}$ Arte legal para estudiar la jurisprudencia, ${ }^{56}$ publicada na cidade universitária de Salamanca, sede do pensamento jurídico espanhol dos séculos XVI e XVII. Pedraza é considerado, por alguns estudiosos, ${ }^{57}$ como um dos epígonos do " $m o s$ italicus", e advertia que "a lei é estabelecida sobre fato duvidoso, porque nos casos claros não é necessária". ${ }^{58} \mathrm{Ou}$ seja, para Pedraza, que escreveu um livro principalmente didático para as futuras gerações de juristas espanhóis, a posição do jurista seria a de alguém que, de per si, lida com a dúvida e não com a certeza.

No capítulo II do seu livro, explicava que para ser um bom jurista era preciso possuir boa memória e ser capaz de saber de cor todas as leis, ${ }^{59}$ porém, no capítulo a seguir, advertia que, na verdade, o jurisprudente precisava ter mais entendimento do que memória, porque, para ser um bom jurista, "não basta saber as leis de memória, mas o seu sentido e a razão delas, e a razão da razão até chegar na fonte e origem da razão natural". ${ }^{60}$ A questão que deveria ser feita e que nos ajudaria a entender o papel da consciência do jurista seria: de que sentido e de que razão estava falando Bermúdez de Pedraza?

Para o jurista espanhol, a razão do direito era ser uma opinião natural ou, como afirma no texto, um "ditame natural", ${ }^{61}$ isto é, a razão de ser do direito não consistia no fato de tratar-se nem da lei divina, nem do instinto humano, nem sequer da lei positiva. Tratava-se de uma opinião raciocinada, argumentada racionalmente, feita pelos jurisprudentes. Ou seja, Bermúdez estava falando que, para dizer o que era justo e adequado numa relação determinada, era preciso ter as condições necessárias para raciocinar corretamente ou, por outras palavras, que o homem, no caso o jurisprudente, devia ser, naturalmente, alguém com boa inteligência porque o ofício do jurista dependia principalmente do "entendimento,

55 Tratei sobre esse autor no texto apresentado no VIII Encontro da ANPHLAC, contudo não discuti, na altura, essa questão: Duas percepções da justiça nas Américas: prudencialismo e legalismo. Anais eletrônicos do VIII Encontro Internacional da ANPHLAC. Vitória, 2008.

${ }^{56}$ BERMÚDEZ DE PEDRAZA, Francisco. Arte legal para estudiar la Jurisprudencia nuevamente corregido y añadido en esta segunda edición. Madrid: por Francisco Martínez, a costa de Domingo Gonçalez, 1633.

57 TAU ANZOÁTEGUI, Victor. Casuísmo y sistema. Indagación histórica sobre el espíritu del derecho indiano. Buenos Aires: Instituto de Investigaciones de Historia del Derecho, 1992, p. 262.

${ }^{58}$ Idem, p. 109.

${ }^{59}$ BERMÚDEZ DE PEDRAZA, Francisco, op. cit., p. 12.

${ }^{60}$ Idem, p. 13.

${ }^{61} \mathrm{O}$ texto exato é: "la razón de la ley es universal, porque es un dictamen natural, al qual todas las gentes obedecen y a todos comprehende, Turcos, Tártaros, Abyssinios y Américos, aunque no estén sujetos al Imperio", p. 20. 
cujo exercício é raciocinar; e, dessa forma, quanto mais capaz de razão for quem estudar essa faculdade, mais apto será para ela". ${ }^{62}$

Essa razão natural não seria uma simples opinião de um jurisprudente. Para decidir conforme a razão eram necessárias, em toda decisão jurídica, oito condições que Bermúdez de Pedraza elencava no capítulo XIII quando tratava "dos primeiros rudimentos da jurisprudência". No "Rudimento XI" explicava cada uma delas: praemitto: distinguir termos equívocos e estabelecer relações; scindo: realizar divisões, summo: reduzir a um sumário; casus: relacionar um caso com a lei; perlego: ler e reler o texto várias vezes; do causas: buscar a razão de decidir, connoto: encontrar a alma da lei inferindo da sua razão para casos semelhantes; e, por último, obiicio: colocar as leis contrárias. ${ }^{63}$

Como se vê, tratava-se de uma arte de raciocinar e de argumentar, porque, para o jurista espanhol, arguir ou argumentar "é o mesmo que mostrar". ${ }^{64} \mathrm{O}$ argumento era uma forma de demonstração utilizada pelos jurisprudentes em que, a partir de uma dúvida fundamentada sobre o direito, davam-se as razões daquilo que ao jurista parecia justo e essa razão que se procurava era a razão da lei nos casos de dúvida, porque "o principal estudo do jurista há de ser inquirir a razão de duvidar em que se fundou o legislador porque sem ela (...) não somente não se podem entender os direitos, mas os que tiverem vários entendimentos, prevalecerá aquele que tiver e tirar maior razão de duvidar". ${ }^{65}$

Para Concina, na metade do século XVIII, o maior problema da vida social e política era o fato de que, para uma lei determinada, sempre se encontravam vários autores, com várias opiniões, muitas vezes opostas. Para Pedraza, no começo do XVII, era nisso, precisamente, que consistia a arte do direito: das várias opiniões e entendimentos, encontrar aquela razão que oferecesse menos dúvida, porque, como o próprio jurista afirmava, "quem argumenta com razão, não argumenta sem lei” ${ }^{66} \mathrm{Na}$ opinião de Paolo Prodi, era nesse momento histórico que se abria a discussão "sobre a relação entre a consciência subjetiva e a lei". ${ }^{67}$

\footnotetext{
${ }^{62}$ Idem, p. 13.

${ }^{63}$ Idem, p. 104-106.

${ }^{64}$ Idem, p. 108.

${ }^{65}$ Idem, op. cit., p. 109.

${ }^{66}$ Ibidem.

${ }^{67}$ PRODI, P., op. cit., p. 209.
} 


\section{A força dos costumes locais}

Durante o século XVII, o direito não era produzido apenas pela lei, mas principalmente pelos costumes locais e pelos fatos que concretizavam e caracterizavam cada caso. No texto do documento conhecido como Apologia pro paulistis, o autor, baseando-se no fato de que as leis reais que estabeleciam a liberdade dos índios não foram registradas pela câmara municipal de São Paulo, defendia que, nesse caso, as leis reais deixavam de ter valor e não se aplicavam na capitania, porque os costumes dos paulistas, ainda que fossem contrários àquelas leis, derrogavam-nas completamente. Apoiava-se, para isso, num texto do jurista medieval Graciano que afirmava que "as leis são instituídas quando são promulgadas, mas se firmam quando comprovadas pelos costumes dos que a praticam". ${ }^{6}$

Para fundamentar ainda mais as suas afirmações e conclusões, o autor da Apologia citava o jurista e moralista jesuíta austríaco Paulo Laymann, nascido em 1574 perto de Innsbruck e morto em 1635. A sua obra, Theologia moralis (1625) foi editada repetidas vezes e, até o final do século XVIII, era usada como livro de texto pelos seminários religiosos.

Para Laymann, o costume podia nascer tanto dos fatos como do direito, e um costume que sempre tivesse sido observado e vivido pelo povo era tanto direito quanto lei, mesmo que esta lei não estivesse escrita. Não seria qualquer fato praticado pelo povo que poderia ter a virtude de gerar o direito ou ser entendido como lei, mas aquele que tivesse sido praticado por mais de dez anos, com o consentimento, pelo menos tácito, do legislador ${ }^{69}$ e que nunca tivesse sido introduzido à força. Dessa forma, configurava-se um "costume imemorial", ${ }^{70}$ do qual não se guardava memória do seu começo. Esse costume era tido como lei e vigorava mesmo contra as leis em contrário. A força do costume, para Laymann, era tão grande que para que as leis pudessem vigorar efetivamente era necessário que fossem aceitas pelo povo. ${ }^{71}$

Finalmente, ao tratar sobre os critérios que deveriam nortear a decisão dos juízes, Laymann explicava que a decisão judicial não poderia apoiar-se apenas na

${ }^{68}$ ZERON, Carlos Alberto de M. R. e RUIZ, Rafael (transcrição e tradução). Apologia pro paulistis. Clio, Revista de Pesquisa Histórica, n. 27-1. Ed. Universitária da UFPE, 2009, p. 400.

${ }^{69}$ Laymann entende que o legislador ou o príncipe consentem e aprovam tacitamente um costume quando, conhecendo-o e podendo-o proibir, toleram-no por um tempo de dez anos. Essa interpretação está fundamentada na Summa theologiae de Tomás de Aquino (I-II, q. 97, a. 3, ad 3).

70 Theologia moralis, 1. I, tr. 4, c. 24, n.7.

${ }^{71}$ Theologia moralis, 1. I, tr. 4, c. 3, n.1. Seguindo a mesma doutrina já apontada de Graciano, afirmava que "as leis se estabelecem com a sua promulgação e se afirmam e comprovam com os costumes daqueles que as utilizam". 
lei, sendo preciso esperar que o uso e a praxe social a legitimassem e os poderes locais a interpretassem: "os juízes não devem decidir as causas, nem no foro interno, nem no externo, de acordo com as leis que não tenham sido recebidas" ${ }^{72}$

Outro autor que analisa o papel dos costumes é o jurista português Domingos Antunes Portugal, que cursou os seus estudos de humanidades e direito na Universidade de Salamanca e foi defensor da Restauração. A sua obra converteu-se num tratado jurídico e político em defesa da mesma. Foi desembargador da Relação do Porto, da Casa da Suplicação (1661) e de Agravos (1664) e, finalmente, deputado do Conselho Ultramarino.

A obra Tractatus de donationibus iurium et bonorum regiae Coronae está estruturada em dois volumes (vol I, 448 p., vol II, 378 p.) e constitui uma exposição detalhada do direito público do século XVII. ${ }^{73} \mathrm{O}$ singular da mesma é que o autor escolhesse um tema de direito privado - a doação - para, a partir daí, realizar uma análise minuciosa de toda a configuração jurídica da Monarquia portuguesa. Não há um tema jurídico que não seja tratado na obra em dois volumes. Há temas claramente de ordem civil ou privada (a diferença entre doação e concessão, os bens que podem ser doados), temas de ordem pública (o patrimônio da Coroa e o patrimônio privado do rei), temas que chamaríamos hoje de constitucionais (a relação entre as Cortes e o rei, a relação de paternidade do rei com os súditos), temas de ordem internacional (a liberdade dos mares, as relações entre Igreja e Estado) ou considerações de ordem jurídica filosófica ou moral (a lei, o justo, a guerra justa, o pecado).

Para o autor, o costume tinha força por si próprio, independentemente da lei. Inclusive, o costume interpretativo, ou seja, a forma costumeira de interpretar uma lei determinada teria vigor e qualquer dúvida sobre a correta interpretação de uma lei resolver-se-ia tendo em conta a maneira como sempre se interpretou. ${ }^{74}$

Há uma passagem interessante com relação à questão de quando é que uma lei passaria a obrigar ao seu cumprimento. Nas províncias (dentro do território de Portugal), o prazo seria de três meses, mas - o autor cita especificamente em Angola, Índia e Brasil, a lei só obrigava quando se passava a ter notícia dela e, mesmo assim, para que houvesse efetiva obrigação legal, seria necessário, nesses lugares, que se mandasse publicar, ${ }^{75}$ fato que nem sempre acontecia.

\footnotetext{
${ }^{72}$ Theologia moralis, 1. I, tr. 4, c. 3, n. 4.

${ }^{73}$ RODRÍGUEZ GIL, Magdalena. Domingos Antunes Portugal. Um jurista barroco. In: Cuadernos de Historia del Derecho, 2004, vol. Extraordinario, 279-292, p. 287.

${ }^{74}$ ANTUNES PORTUGAL, op. cit., n. 99, p. 166.

${ }^{75}$ Ibidem, n. 80, p. 175.
} 
Essa ambiguidade legal, dentro de um contexto, por outro lado, exato e jurídico, fundamenta a hipótese da negociação e das esferas de poder local. Daí que possa se pensar que a própria Coroa contasse com a possibilidade das câmaras municipais não receberem (não terem notícia) das leis da metrópole. Contudo, "não receberem" não apenas no sentido físico - i. é., as leis não chegarem por algum tipo de motivo de "força maior" - mas "não receberem" no sentido forte do termo, quando as câmaras, tendo recebido as leis, não as liam nem as aceitavam e, portanto, não as recebiam.

Da mesma forma que para Laymann, para Antunes Portugal, a opinião de Graciano teria vigência em todo o estatuto legal. $\mathrm{O}$ autor citava o texto em questão expressamente ${ }^{76} \mathrm{e}$ o contrapunha à interpretação de Francisco Suárez para quem a lei obrigava quando era promulgada solenemente. Parece-me que, neste ponto, nos encontramos com as típicas divergências de opinião entre os diferentes juristas e, por isso, tornava-se necessário encontrar e seguir a opinião comum dos doutores ou, como defendia o probabilismo, a opinião provável. De qualquer forma, é significativo que um autor da importância de Antunes, que escreveu um tratado para firmar a legitimidade da Restauração e da separação de Portugal da Coroa de Castela, deixasse de lado Suárez para apoiar-se em Graciano e defender a hipótese de que uma lei que não tivesse sido recebida pelo uso constante do povo não teria, de fato e de direito, força nem nome de lei. ${ }^{77}$

Ainda sobre esse mesmo assunto, o autor afirmava que, para que a lei obrigasse ao seu cumprimento, requerer-se-ia "necessariamente" que fosse aceita pelo povo, porque, de outra forma, a lei não obrigava os súditos ${ }^{78} \mathrm{e}$, em defesa dessa opinião, o jurista indicava uma extensa lista de muitos outros autores que seguiam a mesma opinião e outra lista de autores contrários, que era minoritária.

Lendo Antunes Portugal, pode-se concluir que o tema era, no mínimo, controverso. Contudo, a opinião, se não comum, pelo menos, de muitos autores, era favorável a que as leis necessitavam ser "confirmadas quando aprovadas pelo uso e costume" ${ }^{" 79}$ e, inclusive, as leis eram ab-rogadas, ou seja, deixavam de existir quando não eram vividas. Para Portugal, as leis perdiam a sua força (o seu vigor,

\footnotetext{
${ }^{76}$ ANTUNES PORTUGAL, op. cit., n. 78, p. 175.

${ }^{77}$ Evidentemente, a interpretação de Suárez é muito mais matizada do que o ponto de vista indicado por Antunes Portugal. Sobre esse assunto pode-se ler o artigo de ZERON, Carlos Alberto de M. R. e RUIZ, Rafael. A força do costume, de acordo com a Apologia pro paulistis (1684). ALMEIDA, Marta de e VERGARA, Moema de Rezende (org.). Ciência, história e historiografia. São Paulo/ Rio de Janeiro: Via Lettera/Mast, 2008, p. 359-376.

${ }^{78}$ ANTUNES PORTUGAL, op. cit., n. 87.

${ }^{79}$ Ibidem, n. 88.
} 
no sentido de força e de vigência) quando não eram praticadas, configurando-se um costume contra a lei. O argumento utilizado pelo autor para defender esse ponto de vista era de que as leis eram dadas para a utilidade do bem comum, mas se o povo resistia à lei e não a vivia, a lei não servia e tornava-se necessário a sua ab-rogação. ${ }^{80}$

A conclusão final de Antunes Portugal com relação às leis que, tendo sido editadas não eram recebidas, era de que nenhuma lei deveria ser observada, nem guardada de nenhum modo, e nem sequer o príncipe poderia confirmá-la, mesmo que assim opinasse Suárez, se a mesma não fosse recebida pelo povo. ${ }^{81}$

Em resumo, durante o século XVII, o costume não era visto apenas como uma fonte de direito que devia ter-se em conta à hora do juiz formular a sua sentença, mas também era entendido, por um grande número de juristas, como a fonte legitimadora para que as leis reais pudessem obrigar ao seu cumprimento de forma coativa. Se a maior parte do povo não praticasse, de fato, a conduta exigida pela lei, era a lei que não entrava em vigor e não, como poderia pensarse, o povo quem desobedecia à vontade real configurada na mesma.

\section{Conclusão}

Nem todos os juristas do século XVII estavam inseridos na corrente de pensamento probabilista. Contudo, parece-me que, diante da pesquisa apresentada, pode-se afirmar que um bom número deles - cobrindo todo o espectro cronológico do século -, o suficientemente representativos para que as suas obras tivessem várias edições e fossem citadas por outros juristas e moralistas, partilhava da ideia de que as leis não deviam ser aplicadas ao pé da letra, mas, ao contrário, precisavam de uma interpretação que passava pelo crivo dos costumes locais e da opinião provável dos doutores.

Essa forma de entender o fenômeno jurídico não era apenas algo específico desses autores, mas fazia parte do próprio sistema jurídico e era aceito, em maior ou menor grau, pela própria Coroa. Era uma forma de relativizar as leis e, adaptando-as e interpretando-as, praticar a justiça nas diferentes partes do Império, conforme as necessidades e os interesses locais. Tratava-se, portanto, de uma forma de entender a praxe judiciária que não significava, necessariamente, uma oposição nem um descaso ou enfrentamento com as autoridades metropolitanas. Podia muito bem significar o exercício legal e legítimo da própria esfera

\footnotetext{
${ }^{80}$ Ibidem, n. 88.

${ }^{81}$ Ibidem, n. 89, p. 176.
} 
de autonomia que os poderes locais gozavam no exercício da aplicação das leis reais, dentro de uma ampla margem de ambiguidade.

Pode-se, portanto, afirmar com certa segurança que, ao contrário do que uma parte da historiografia pensa sobre a legislação colonial, a América do século XVII foi o lugar onde as autoridades locais podiam usar e usavam, de fato e de forma legítima, de um arcabouço jurídico e interpretativo que lhes permitia negociar, adaptar, recriar e, inclusive, rejeitar as leis emanadas da metrópole.

\section{Referências bibliográficas}

\section{A. Fontes impressas}

AGIA, Miguel. Servidumbres personales de indios. Edição e estudo preliminar de Francisco Javier Ayala. Sevilla: Publicaciones de la Escuela de Estudios Hispanoamericanos, 1946.

BERMÚDEZ DE PEDRAZA, Francisco. Arte legal para el estúdio de la jurisprudência. Salamanca: Imprenta de Antonia Ramírez, Viúda, 1612.

BERMÚDEZ DE PEDRAZA, Francisco. Arte legal para estudiar la jurisprudencia nuevamente corregido y añadido en esta segunda edición. Madrid: por Francisco Martínez, a costa de Domingo Gonçalez, 1633.

CABEDO, Jorge de. Practicarum observationum sive decisionum supremi senatu Regni Lusitaniae. Antuerpiae: Ioannem Keerbergium, 1620.

CASTILLO DE BOBADILLA, Jerônimo. Política para corregidores y señores de vasallos en tiempos de paz y de guerra. Medina del Campo: por Christoval Lasso e Francisco Garcia, 1608.

CERDÁN DE TALLADA, Thomás. Veriloquium en reglas de Estado, segun derecho diuino, natural, canonico y ciuil y leyes de castilla, enderezado a la conseruacion de la auctoridad del catholico don Phelipe Tercero. Valencia: en casa de Iuan Chrysostomo Garriz, 1604.

CONCINA, Daniel, Theologia christiana dogmático-moral, compendiada en dos tomos. Traducida al idioma castellano y añadida en muchas partes de las obras del mismo autor por el p. d. Joseph Sánchez de la Parra. Madrid: Tercera Impresión, en la oficina de la viúda de Manuel Fernández, 1773.

LAYMANN, P., Theologia moralis in quinque libros partita. Bambergae: Editio Sexta, Joan Martius Schonwetteri, 1677.

PORTUGAL, Domingos Antunes. Tractatus de donationibus iurium et bonorum regiae Coronae. Lugduni: Editio secunda Lugdinensis, Adisson, 1699. 


\section{B. Bibliografia complementar}

ARANDA PÉREZ, Francisco José e RODRIGUES, José Damião (eds.). De re publica Hispaniae. Una vindicación de la cultura política en los reinos ibéricos de la primera Modernidad. Madrid: Sílex, 2008.

HOMEM, António Pedro Barbas. Judex perfectus. Função jurisdicional e estatuto judicial em Portugal, 1640-1820. Coimbra: Almedina, 2003.

MARTEL PAREDES, Víctor Hugo. El lugar del probabilismo en las ideas políticas del Perú. Solar. Lima, nº 3, año 3, 2007.

MUÑOZ GARCÍA, Ángel. Diego de Avendaño, 1594-1698: filosofía, moralidad, derecho y política en el Perú colonial. Lima: UNMSM, Fondo Editorial, 2003.

PRODI, Paolo. Uma história da justiça. Do pluralismo dos foros ao dualismo moderno entre consciência e direito. Tradução de Karina Jannini. São Paulo: Martins Fontes, 2005.

RUIZ, Rafael. Duas percepções da justiça nas Américas: prudencialismo e legalismo. Anais eletrônicos do VIII Encontro Internacional da ANPHLAC. Vitória, 2008.

SUÁREZ. Francisco. De Legibus III. Madrid: Corpus Hispanorum de Pace, 1974.

TAU ANZOÁTEGUI, V. Casuismo y sistema. Indagación histórica sobre el espíritu del derecho indiano. Buenos Aires: Instituto de Investigaciones de Historia del Derecho, 1992.

VILLEY, M. A formação do pensamento jurídico moderno. Tradução de Cláudia Berliner. São Paulo: Martins Fontes, 2005.

ZERON, Carlos Alberto de M. R. e RUIZ, Rafael (transcrição e tradução). Apologia pro paulistis. Clio, Revista de Pesquisa Histórica, n. 27-1. Ed. Universitária da UFPE, 2009.

ZERON, Carlos Alberto de M. R. e RUIZ, Rafael. A força do costume, de acordo com a Apologia pro Paulistis (1684). In: ALMEIDA, Marta de e VERGARA, Moema de Rezende (org.). Ciência, história e historiografia. São Paulo/Rio de Janeiro: Via Lettera/Mast, 2008, p. 359-376.

ZERON, Carlos Alberto de Moura Ribeiro. Ligne de foi: La Compagnie de Jésus et l'esclavage dans le processus de formation de la société coloniale en Amérique portugaise (XVIe.-XVIIe. siécles). Paris: Honoré Champion Éditeur, 2009.

Recebido: 09/11/2009 - Aprovado: 24/05/2010. 